\title{
Relationship between amorphous silica in source materials and compressive strength of geopolymer concrete
}

\author{
Basil Al-Shathr ${ }^{1}$, Mohamed Shamsa ${ }^{1, *}$, and Tareq al-Attar ${ }^{1}$ \\ University of Technology, 10066, Baghdad, Iraq
}

\begin{abstract}
Geopolymer is a new sustainable binding material. It was developed to reduce $\mathrm{CO}_{2}$ footprint of existing Portland cement concrete. One ton of Geopolymeric cement generates 0.18 ton of $\mathrm{CO}_{2}$ from combustion carbon-fuel. This figure is 6 times less than the emission of Portland cement manufacture. The relationship between the compressive strength of Geopolymer concrete and the percentage of amorphous silica in the source material has been studied in the present work. Six mixes with different source materials were investigated to verify this relationship. The used Pozzolanic materials were three types of Fly ash, two types of Metakaolin and one type of ground granulated blast furnace slag. Geopolymer concrete samples were cured by heating for 72 hours. The testing ages for compressive strength were 7, 14, 28, and 60 days. The results showed that a noticeable relationship between compressive strength and amorphous silica was observed. The microstructure of the six mixes was studied in detail through the SEM and XRD analysis.
\end{abstract}

\section{Introduction}

Davidovits [1] stated that the geopolymerization process involves a reaction between alkaline liquids and compounds containing alumina and silica to produce a binder. The binder is termed "Geopolymer". Unlike ordinary Portland /Pozzolanic cements, Geopolymer do not form calcium-silicate-hydrates (CSHs) for matrix formation and strength, but the aluminosilicate gel forms by Geogeopolymerization binds the aggregates and provides the strength to Geopolymer concrete. The strength of Geopolymer depends on the composition of its constituent materials [2]. Natural or by-product materials containing silicon ( $\mathrm{Si}$ ) and aluminum ( $\mathrm{Al})$ in amorphous form could be used as source materials for Geopolymer.

Palomo et al. [3] indicated that this new cementitious material is an amorphous alkali silicoaluminate (containing small proportions of quartz, mullite, and maghemite from the original Fly ash), similar to that obtained in the alkali activation of Metakaolin.

During the first step of the reaction, the amorphous portion of the Fly ash begins to dissolve; in accordance with the FTIR results, the $\mathrm{Al}$ in tetrahedral coordination reacts but the $\mathrm{Al}$ in octahedral coordination does not.

Duxson et al. [4] showed that the fundamental chemical and structural characteristics of Geopolymers derived from Metakaolin, Fly ash and slag are explored in terms of the effects of raw material selection on the properties of Geopolymer composites. It was shown that the raw materials and processing conditions are critical in determining the setting behavior, workability and chemical and physical properties of Geopolymeric products. The XRD diffractogram labeled b in Fig. 1 is of a Geopolymeric gel with nominal composition $\mathrm{NaAlSiO}_{4}$, synthesized from Metakaolin (diffractogram a) in a $35 \mathrm{wt} \%$ water activating solution at 40 C, 1 day after synthesis. Although this material appears amorphous to XRD initially, evidence of the same reaction mechanism being responsible for the formation of Geopolymer and crystalline zeolite can be observed, with the formation of zeolite observed within 7 days of synthesis (diffractogram c). Similar results obtained when Fly ash (diffractogram d) is used as activated material, as seen in Fig.1 (diffractogram e and f).

The compressive strength of Geopolymer concrete is not dependent only on the presence of silica in raw materials, whereas the alumina has main function and active in strength acquisition. De Silva et al. [5] showed that setting time of the Geopolymer systems was mainly controlled by the alumina content. Essentially, the setting time increased with increasing $\mathrm{SiO}_{2} / \mathrm{Al}_{2} \mathrm{O}_{3}$ ratio of the initial mixture. Up to a certain limit, the $\mathrm{SiO}_{2} / \mathrm{Al}_{2} \mathrm{O}_{3}$ ratio also found to be responsible for observed high-strength gains at later stages. An increase in the $\mathrm{Al}_{2} \mathrm{O}_{3}$ content, i.e. for low $\mathrm{SiO}_{2} / \mathrm{Al}_{2} \mathrm{O}_{3}$ ratio, led to products of low strength.

Saidi et al. [6] studied the effect of $\mathrm{Si} / \mathrm{Al}$ and $\mathrm{Na} / \mathrm{Al}$ ratios on mechanical properties of Metakaolin based Geopolymer. There results indicated that an increase of $\mathrm{Si} / \mathrm{Al}$ ratio improves the Geopolymer mechanical properties due probably to the formation of $\mathrm{Si}-\mathrm{O}-\mathrm{Si}$ bond in the Geopolymer at the expense of $\mathrm{Si}-\mathrm{O}-\mathrm{Al}$ one. It was also shown that an introduction of $\mathrm{NaOH}$ in the Geopolymer composition enhances the mechanical properties until a molar ratio of $\mathrm{Na} / \mathrm{Al}=1$. Beyond this value, the excess of $\mathrm{Na}+$ cation causes fragility of the

Corresponding author: mhshamsa990@gmail.com 
Geopolymer structure confirmed by a decrease of the mechanical strength.

The objective of this paper was to study the effect of amorphous silica in different source materials on the strength development of Geopolymer concrete.

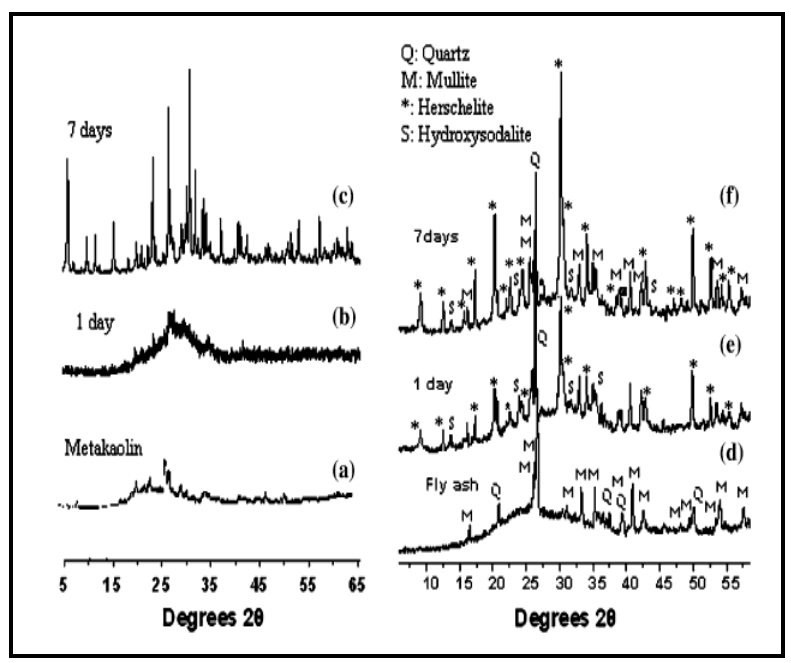

Fig. 1. XRD diffractogram of (a) typical Metakaolin (with slight muscovite impurity), (b) Geopolymer with nominal composition $\mathrm{NaAlSiO}_{4}$ obtained after 1 day and (c) 7 days after synthesis, showing peaks corresponding to zeolite $\mathrm{X}$, (d) typical Fly ash, (e) inorganic polymer from Fly ash at $20 \mathrm{~h}$, $85^{\circ} \mathrm{C}$ and (f) 7 days at $85^{\circ} \mathrm{C}$ [4]

\section{Experimental work}

\subsection{Materials}

The following materials have been used in the production of Geopolymer concrete:

\subsubsection{Source materials (Pozzolanic materials)}

- Three types of Fly ash used (FA1) from China and (FA2, FA3) from electrical power plant in Turkey.

- Two types of Metakaolin (MK1, MK2); the M.K. derived from kaolin by calcination at $700^{\circ} \mathrm{C}$ for 2 hours. The raw kaolin brought from Al-Ramadi region in Iraq. - Ground granulated blast furnace slag (GGS).

The chemical composition of the Pozzolanic materials determined by XRF analysis is given in Table (1). Fig. 2. shows the XRD patterns of these source materials.

\subsubsection{Alkaline solution}

Alkaline solution was obtained by blending sodium silicate and sodium hydroxide solutions.

- Sodium silicate with chemical composition of $\mathrm{Na}_{2} \mathrm{O}=$ $13.5 \%, \mathrm{SiO}_{2}=32.5 \%, \mathrm{H}_{2} \mathrm{O}=54 \%$.

- Sodium hydroxide $\mathrm{NaOH}$ flakes with $97-98 \%$ purity used. The sodium hydroxide solution was prepared by dissolving the $\mathrm{NaOH}$ flakes in tap water to produce an $8 \mathrm{M}$ solution.

\subsubsection{Aggregate}

Crushed gravel with $12.5 \mathrm{~mm}$ maximum size used, as coarse aggregate, natural graded sand was the fine aggregate according to ASTM C33 [7], as shown in Tables 2 and $3 . \mathrm{SO}_{3}$ contents were 0.39 and $0.07 \%$ for fine and coarse aggregate respectively.

\subsubsection{High-range water reducer}

A high range water reducer superplasticizer (KUT PLAST SP400) based on modified sulphonated naphthalene formaldehyde condensate was used to enhance workability of Geopolymer concrete.

Table 1. Chemical composition of the used Pozzolanic materials.

\begin{tabular}{|c|c|c|c|c|c|c|}
\hline $\begin{array}{c}\text { Oxides } \\
\text { \% }\end{array}$ & FA1 & FA2 & FA3 & MK1 & MK2 & GGS \\
\hline $\mathrm{SiO}_{2}$ & 50.5 & 60.6 & 63.0 & 53.30 & 56.77 & 30.7 \\
\hline $\mathrm{Al}_{2} \mathrm{O}_{3}$ & 22.7 & 31.7 & 27.1 & 34.63 & 30.85 & 13.3 \\
\hline $\mathrm{Fe}_{2} \mathrm{O}_{3}$ & 6.33 & 3.98 & 4.12 & 2.21 & 2.48 & 0.35 \\
\hline $\mathrm{CaO}$ & 13.8 & 0.98 & 1.20 & 0.94 & 0.58 & 42.4 \\
\hline $\mathrm{MgO}$ & 1.22 & 0.72 & 0.74 & 0.32 & 0.59 & 6.89 \\
\hline Others & 5.42 & 1.98 & 3.71 & 8.6 & 8.73 & 6.32 \\
\hline
\end{tabular}

Table 2. Sieve analysis of coarse aggregate

\begin{tabular}{|c|c|c|}
\hline Sieve size ( mm) & $\begin{array}{c}\text { Passing } \\
\mathbf{( \% )}\end{array}$ & $\begin{array}{c}\text { ASTM C-33[6] } \\
\text { Requirements }\end{array}$ \\
\hline 19 & 100 & 100 \\
\hline 12.5 & 98.5 & $90-100$ \\
\hline 9.5 & 63.9 & $40-70$ \\
\hline 4.75 & 2.7 & $0-15$ \\
\hline 2.36 & 0.2 & $0-5$ \\
\hline $\begin{array}{c}\text { Percentage } \\
\text { materials less than } \\
75 \text { micron }\end{array}$ & 0.66 & $1 \%$ upper limit \\
\hline
\end{tabular}

Table 3. Sieve analysis of fine aggregate.

\begin{tabular}{|c|c|c|}
\hline $\begin{array}{c}\text { Sieve size } \\
(\mathbf{~ m m})\end{array}$ & $\begin{array}{c}\text { Passing } \\
\mathbf{( \% )}\end{array}$ & $\begin{array}{c}\text { ASTM C-33[6] } \\
\text { Requirements }\end{array}$ \\
\hline 9.5 & 100 & 100 \\
\hline 4.75 & 98.2 & $95-100$ \\
\hline 2.36 & 90.8 & $80-100$ \\
\hline 1.18 & 73.3 & $50-85$ \\
\hline 0.6 & 52.3 & $25-60$ \\
\hline 0.3 & 15.1 & $5-30$ \\
\hline 0.15 & 4.2 & $0-10$ \\
\hline $\begin{array}{c}\text { Percentage } \\
\text { materials less } \\
\text { than 75 micron }\end{array}$ & 1.98 & $3 \%$ upper limit \\
\hline
\end{tabular}

\subsection{Mixing and specimen preparation}

Six series of Geopolymer concrete mixes were produced by varying the Pozzolanic material type, as shown in Table 4.

First the alkaline activators with $8 \mathrm{M}$ (sodium silicate, sodium hydroxide, water and superplasticizer) were 
prepared. The proportion of $\mathrm{NaOH}$ to $\mathrm{Na}_{2} \mathrm{SiO}_{3}$ was $1: 1.5$ for FA and GGS mixes, while it was 1:2 for MK mix to obtain workable mixes. The dry materials (Pozzolanic material, fine and coarse aggregates) were mixed in a mixer for 4 mins to have the required homogeneity. The alkaline activators were then poured into the mixer and mixed continuously for approximately 4 mins until the concrete was well-mixed. The fresh concrete then was cast in two layers in steel cylinder molds of $100 \mathrm{~mm}$ diameter and $200 \mathrm{~mm}$ height and vibrated for two mins for each layer on vibrating table to remove entrapped air.

Table 4. Mix proportions of Geopolymer concrete.

\begin{tabular}{|c|c|c|c|}
\hline $\begin{array}{c}\text { Materials } \\
\left(\mathbf{k g} / \mathbf{m}^{\mathbf{3}} \mathbf{)}\right.\end{array}$ & $\begin{array}{c}\text { FA1, } \\
\text { FA2, } \\
\text { FA3 }\end{array}$ & $\begin{array}{c}\text { MK1, } \\
\text { MK2 }\end{array}$ & GGS \\
\hline $\begin{array}{c}\text { Pozzolanic } \\
\text { material }\end{array}$ & 400 & 400 & 400 \\
\hline $\mathrm{NaOH}$ & 19 & 26 & 36 \\
\hline Sodium Silicate & 111 & 200 & 150 \\
\hline Water & 55 & 74 & 65 \\
\hline Fine aggregate & 650 & 650 & 650 \\
\hline Coarse aggregate & 1200 & 1200 & 1200 \\
\hline Superplasticizer & 12 & 12 & 12 \\
\hline
\end{tabular}

\subsection{Curing and testing procedures}

The molded specimens were placed in the oven for 24 hours, after that they were taken out and removed from their molds. After that, they additionally cured in the oven for another 48 hours. Fly ash based Geopolymer, GGBS based Geopolymer cured at $70 \pm 5^{\circ} \mathrm{C}$ and the Metakaolin based Geopolymer cured at $45 \pm 5^{\circ} \mathrm{C}$, according to the recommendations of Alhifadhi [8] and Al-Shathr et al. [9]. The specimens removed out and allowed to cure at room temperature $\left(20 \pm 5^{\circ} \mathrm{C}\right)$ until testing their compressive strength using a digital compression testing machine at 3,7,28, and 60 days age. The reported compressive strength is average strength of three specimens.

\section{Results and discussion}

\subsection{Compressive strength}

Table 5 and Fig. 2 indicate the compressive strength of Geopolymer concrete mixes. In all cases, the strength of the concrete increased with age. The rate of strength gain is high at early ages and gradually decreases at later ages.

Five types of Geopolymer concrete studied to know the effect of amorphous silica content in the raw materials on compressive strength development. The three types of Fly ash based Geopolymer, FA1*, FA2* and FA3*, have differences in their compressive strength at all ages. Fly ash used in mixes FA2* and FA3* have approximately the same chemical compositions and surface area, as shown in Tables 1 and 6 . Therefore, it was expected that both mixes should have a similar strength.

Table 5. Compressive strength of Geopolymer concrete mixes.

\begin{tabular}{|c|c|c|c|c|c|c|}
\hline \multirow{2}{*}{$\begin{array}{c}\text { Age } \\
\text { days }\end{array}$} & \multicolumn{6}{|c|}{$\begin{array}{c}\text { Compressive strength of concrete mixes } \\
\text { containing pozzolanic material type, MPa }\end{array}$} \\
\cline { 2 - 7 } & FA1 & FA2 & FA3 & MK1 & MK2 & GGS \\
\hline $\mathbf{7}$ & 44.7 & 34.49 & 40.56 & 19.38 & 22.70 & 40.00 \\
\hline $\mathbf{1 4}$ & 53.92 & 46.21 & 52.12 & 22.12 & 27.84 & 48.40 \\
\hline $\mathbf{2 8}$ & 65.40 & 52.28 & 61.02 & 26.57 & 35.44 & 52.66 \\
\hline $\mathbf{6 0}$ & 65.27 & 52.35 & 61.75 & 27.36 & 36.10 & 51.96 \\
\hline
\end{tabular}



Fig. 2. Effect of age on compressive strength of Geopolymer concrete mixes

From the XRD results for raw materials, shown in Fig. 3, there is a difference in the amount of amorphous silica which is indicated by the hump in the chart. It is proposed that these differences could be the result of varying furnace temperatures or changes in the feed coal composition. The $\mathrm{Si} / \mathrm{Al}$ ratio in FA2 mix is lower than FA3, so according to De Silva et al. [5] the $\mathrm{SiO}_{2} / \mathrm{Al}_{2} \mathrm{O}_{3}$ ratio could be responsible for the observed high-strength gain. On the other hand, the higher content of calcium compounds in FA1 compared to others is thought to be the second factor that was attributing to the faster strength development of mix containing FA1. The formation of calcium silicate, calcium aluminate hydrates [10], and calcium-silico-aluminates [11] is possible, and in many cases, the high early strengths achieved with blended Geopolymeric cements ascribed to the formation of these compounds. Further evidence that supports this statement is the slag based Geopolymers, GGS*, which contains both amorphous and semi crystalline newly formed phases contained calcium.

The GGS* mix showed higher strength than FA2* mix especially at early age, 14 days, and that could be due to high content of calcium compounds in GGS.

Table 6. Specific surface area of the used Pozzolanic materials.

\begin{tabular}{|l|l|l|l|l|l|l|}
\hline Material & FA1 & FA2 & FA3 & MK1 & MK2 & GGS \\
\hline
\end{tabular}




\begin{tabular}{|c|c|c|c|c|c|c|}
\hline $\begin{array}{c}\text { Fineness } \\
\left(\mathrm{m}^{2} / \mathrm{kg}\right)\end{array}$ & 765 & 773 & 778 & 16800 & 17250 & 681 \\
\hline
\end{tabular}

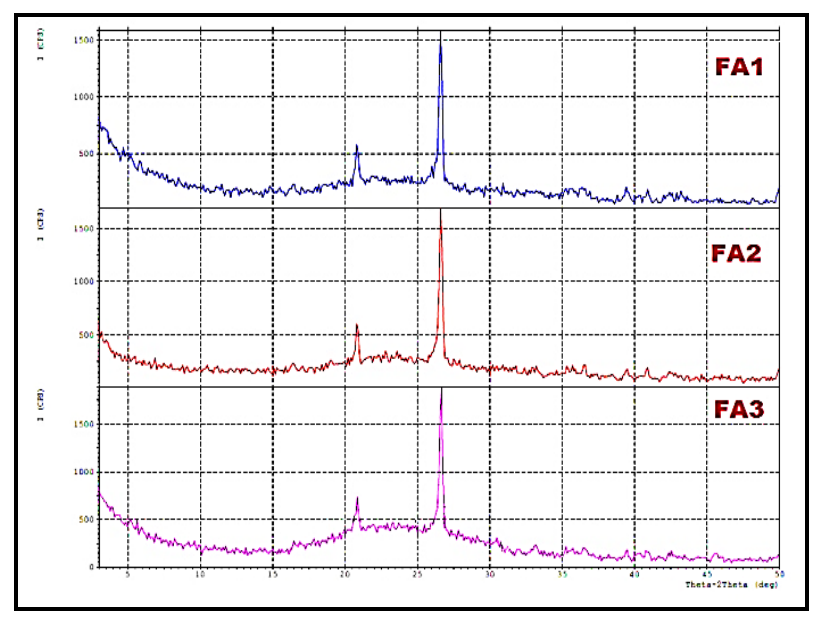

Fig. 3. XRD pattern of the used Fly ashes.

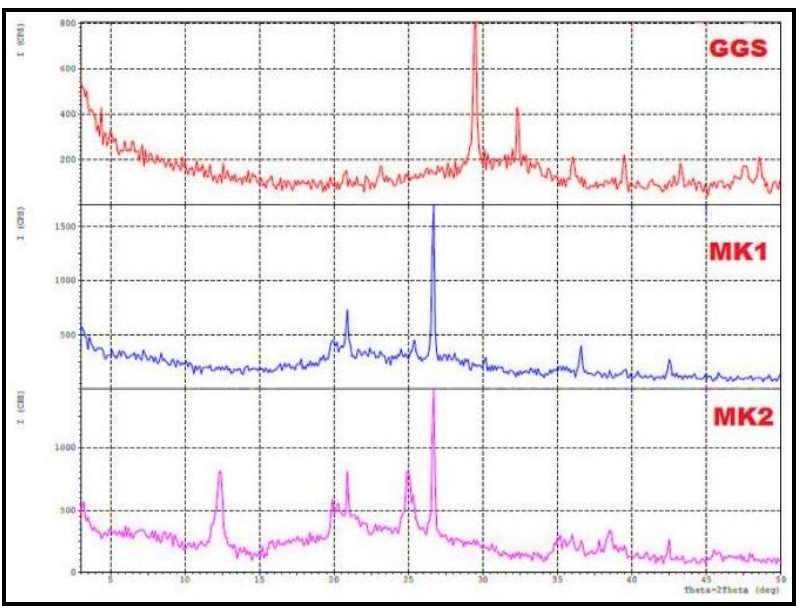

Fig. 4. XRD pattern of the used Metakaolin and GGS.

In MK1 and MK2 mixes [6] the results of XRD analysis of Metakaolin as shown in Fig. 4 displayed a revealing hump pattern in the range of $15^{\circ}$ to $30^{\circ}(2 \theta)$. This hump indicates that these materials are amorphous.

Some peaks related to crystallized phases were also detected, which is attributed to quartz and elite initially present in the kaolin and which did not contributed to the geopolymerization. The diffractogram of the MK2 shows some peaks which are not present in the MK1 spectra which are indicating more orderly phases in this material.

\subsection{Geopolymerization microstructure}

products

and

The products of geopolymerization of concrete mixes can be generally traced by using XRD and EDX analysis combined with scanning electron microscope, SEM, images. Figs. 5 and 6 illustrate the XRD analysis of Fly ash, Metakaolin, and GGS based Geopolymers in 60 days age.

Main crystalline phases observed in the Fly ash Geopolymer samples are quartz, mullite and are largely unaffected by the geopolymerization process. By linking the results between XDR analysis and ESM images and EDX analysis, it could be noticed that the FA1* sample showed crystalline needles Fig. (7-a, b), especially in early ages, similar to the needles formed during the reaction of the Portland cement. This may be due to the high $\mathrm{CaO}$ ratio, which was $14 \%$ in the XRF analysis, Table 1. Meanwhile, its ratio was in the EDX analysis for Geopolymer concrete is 3.25 , which is a high ratio compared to the samples FA2* and FA3*, which were 1.83 and 1.62 respectively.

From the XDR analysis at 60 days for mix FA1* Geopolymer concrete sample Fig. 5, it is worthy to point out to the emergence of peaks representing the formation of $\mathrm{C}_{2} \mathrm{~S}$ gel in $2 \theta$ equals to $28^{\circ}$ and $46.5^{\circ}$.

From the XDR analysis of the raw material, Fig. 3, the sample FA2, had higher percentage of the crystallized silica than FA3. After two months, the XRD analysis shows the high rise in the intensity of the quartz for FA2* Geopolymer concrete. The SEM images for FA2* in Fig.7-c, d showed the appearance of the crystallized material clearly and the emergence of many voids in early ages that may reduce the compressive strength.

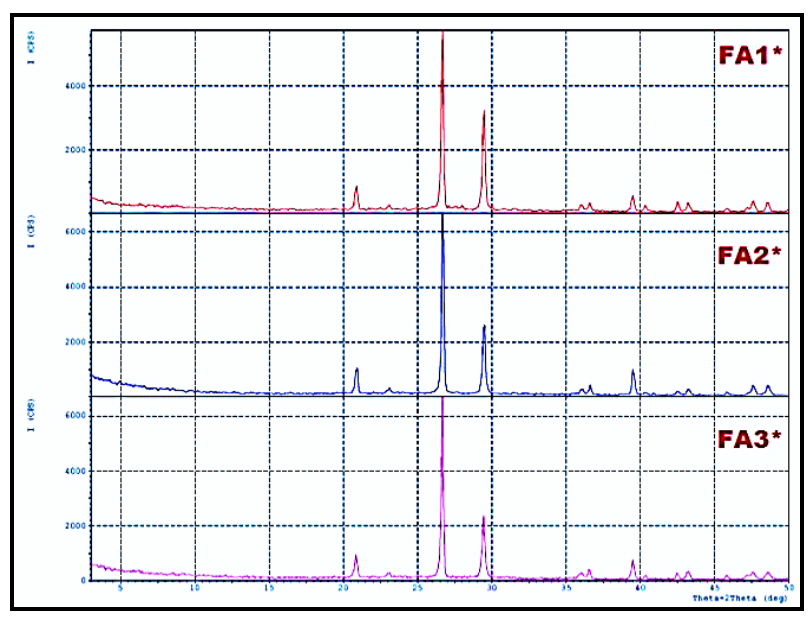

Fig. 5. XRD of Fly ash Geopolymer concrete after 28 days.

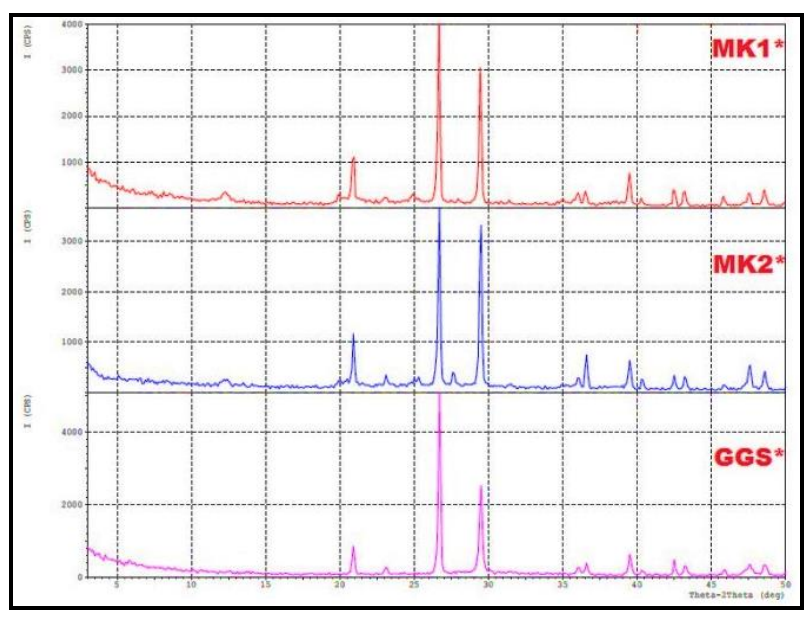

Fig. 6. XRD pattern of Metakaolin and GGS Geopolymer concrete at age of 28 days 
The increase of the elements $(\mathrm{Si}, \mathrm{Al}, \mathrm{Na}$, and $\mathrm{Ca})$ in the EDX analysis indicates an increase in compressive strength, where, at low $\mathrm{Si}$, low compressive strength achieved only if the silica already present in the crystalline material is not involved in the geopolymerization process. When comparing the FA2* sample FA $3 *$ samples, it could be noted that the ratios of the aforementioned elements in the EDX analysis of FA3* sample are higher, resulting in increased compressive strength during the age of the examination. The XRD analysis of the raw Metakaolin samples in Fig. 4 showed that MK2 has a higher ratio of the amorphous silica, which is clear from the hump in the pattern. When analyzing two month old Geopolymeric concrete samples, the crystallization intensity of MK1* is much higher than that of MK2*. This indicates that silica, which crystallized in MK1, did not contribute to geopolymerization, resulting in reduced compressive strength as observed in Table 5 in all ages.

SEM images in Fig. 8 a-d showed a clear manifestation of the amount of silica crystallized in the MK1* sample. From the EDX analysis, it could be noted that the ratio of elements $\mathrm{Si}, \mathrm{Al}, \mathrm{Na}$, and $\mathrm{Ca}$ in the $\mathrm{MK} 2 *$ sample is higher than $\mathrm{MK} 1 *$ at the age of two weeks. In a system with a high $\mathrm{Si}$ concentration, condensation starts with the formation of oligomeric silicates, leading to 3-D rigid polymeric structures. Low $\mathrm{Si}$ concentration results in poly-sialate polymer structures, and confirms that crystallized silica originally present in MK1 did not contribute to geopolymerization so the Si percent was high in two months old. In addition, the $\mathrm{Si} / \mathrm{Al}$ ratio may be considered as the second indicator on the increase in strength, it is clear from the EDX analysis that the ratio in the sample MK2* at the age of 2 months was about 3.43 and about 1.92 in the MK1* sample.

For the GGS* sample, calcium oxide plays a major role in the process of strength development. Moreover, the absence of quartz in the XRD analysis of GGS material in Fig. 4 is evidence on the process of consumption of amorphous silica. According to SEM images and EDX analysis of the GGS* Geopolymer concrete samples, Figs. 10-e, f, there is no quartz and low Si ratio during the age, where 19.01 at two weeks to 9.92 at the age of two months. The $\mathrm{C}_{3} \mathrm{~S}$ and $\mathrm{C}_{2} \mathrm{~S}$ gel as evident in the XRD analysis in Fig. 7 as well as the calcium aluminate hydration gel appearance at $\left(2 \theta \approx 42.5^{\circ}\right)$.

\section{Conclusions}

The following conclusions can be drawn from this study: 1. The ratio of amorphous silica in the raw Pozzolanic material has a significant effect on the compressive strength of the copolymer concrete.

2. The ratio of quartz (crystalline silica) found in the raw Pozzolanic material does not contribute to the process of geopolymerization and therefore will be high also after the formation of Geopolymer concrete.

3. The ratio of $\mathrm{Ca}$ in the raw material has an effect on increasing compression resistance in early ages, as it contributes to the formation of gel-like gel resulting from the hydration of cement.

4. Increasing the $\mathrm{Si}, \mathrm{Al}, \mathrm{Na}, \mathrm{Ca}$ elements in the Geopolymer concrete has an indication of increased compressive strength.

5. The high Si ratio of EDX analysis of the Geopolymer concrete is not necessarily indicative of increased compressive resistance unless the silica present in the raw material is amorphous silica.

6. The properties of a Geopolymer can be significantly by relatively minor changes in $\mathrm{Si}$ and $\mathrm{Al}$ concentrations during synthesis, where increasing the $\mathrm{Si} / \mathrm{Al}$ ratio to a certain extent leads to increased compressive resistance.

\section{References}

1. J. Davidovits, Geopolymer chemistry and applications, (Inst. Geop., France 2011)

2. S. Wallah, B. Rangan, Curtin Uni. Tech. (2006)

3. A. Palomo, M. Grutzeck, M. Blanco, Cem. Conc. Res, 29, 8 (1999)

4. P. Duxson, A. Fernández-Jiménez, J. Provis, G. Lukey, A. Palomo, J. van Deventer, J. Mat. Sci., 42, 9 (2007)

5. P. De Silva, K. Sagoe-Crenstil, V. Sirivivatnanon, Cem. Conc. Res. 37, 4 (2007)

6. N. Saidi, B. Samet, S. Baklouti, Int. J. Mat. Sci., 3, 4 (2013)

7. ASTM C33-15, Annual Book of ASTM Standards (2015)

8. M. Alhifadhi, MSc thesis, Uni. Tech., Iraq (2015)

9. B. Al-Shathr, T. al-Attar, Z. Hasan, J. Babylon Uni.

24 (2016)

10. M. Luxán, M. Sánchez de Rojas, M. Frías, Cem. Conc. Res., 19, 1 (1989)

11. J. Davidovits, J. Mat. Edu.16 (1994) 

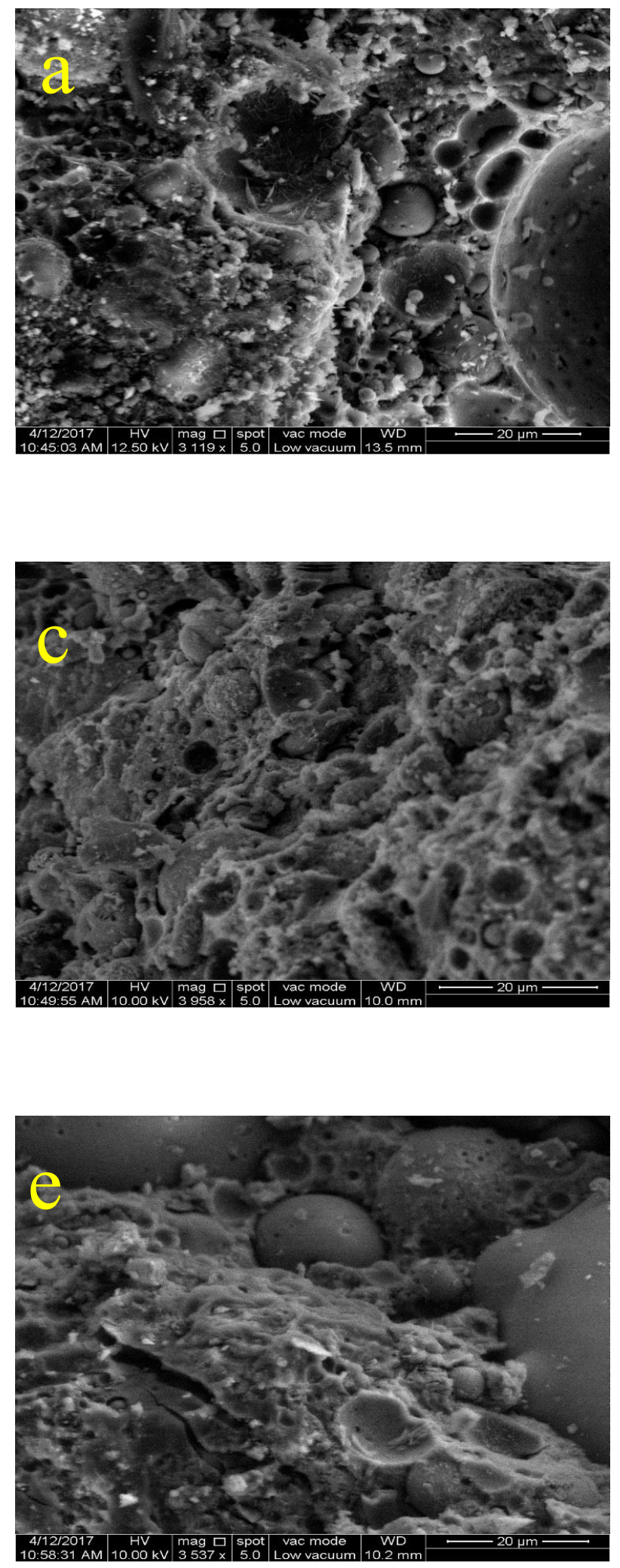
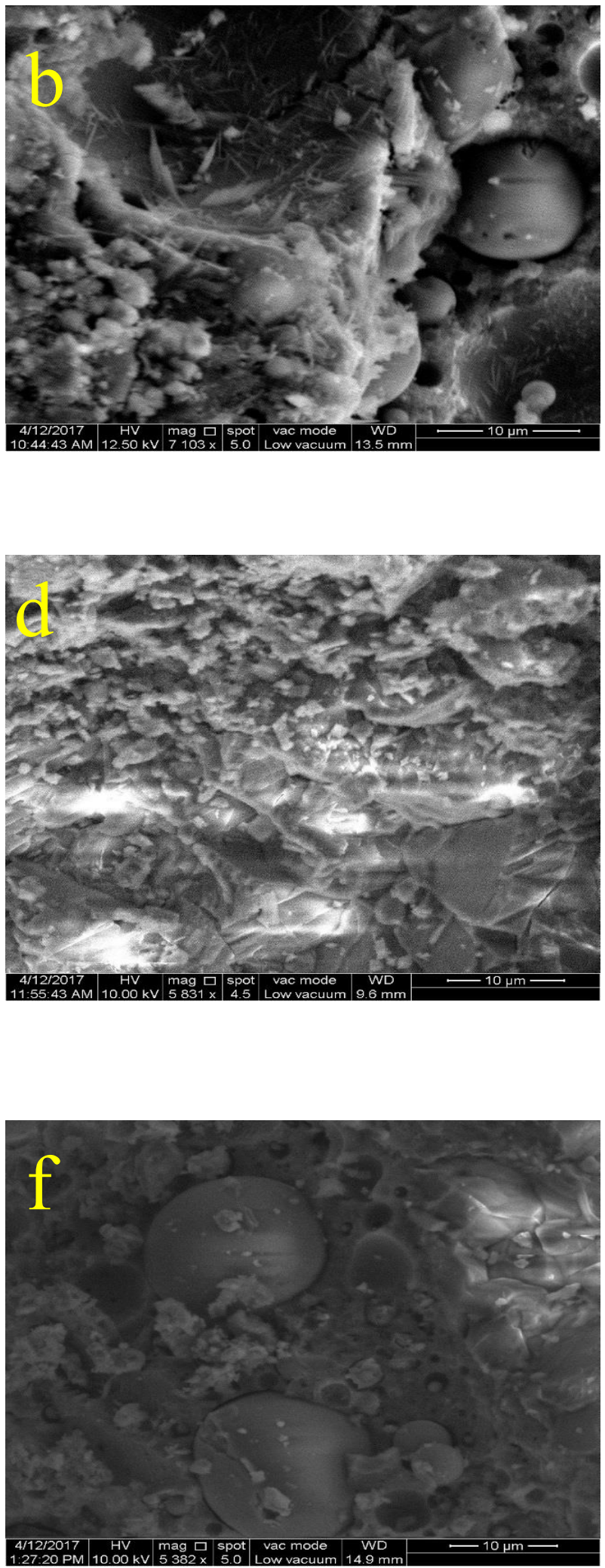

Fig.7. SEM pictures for fly ash based Geopolymer concrete; (a) FA1* at 14 days, (b) FA1* at 60 days, (c) FA2* at 14 days, (d) FA2* at 60 days, (e) FA3* at 14 days, and (f) FA3* at 60 days 

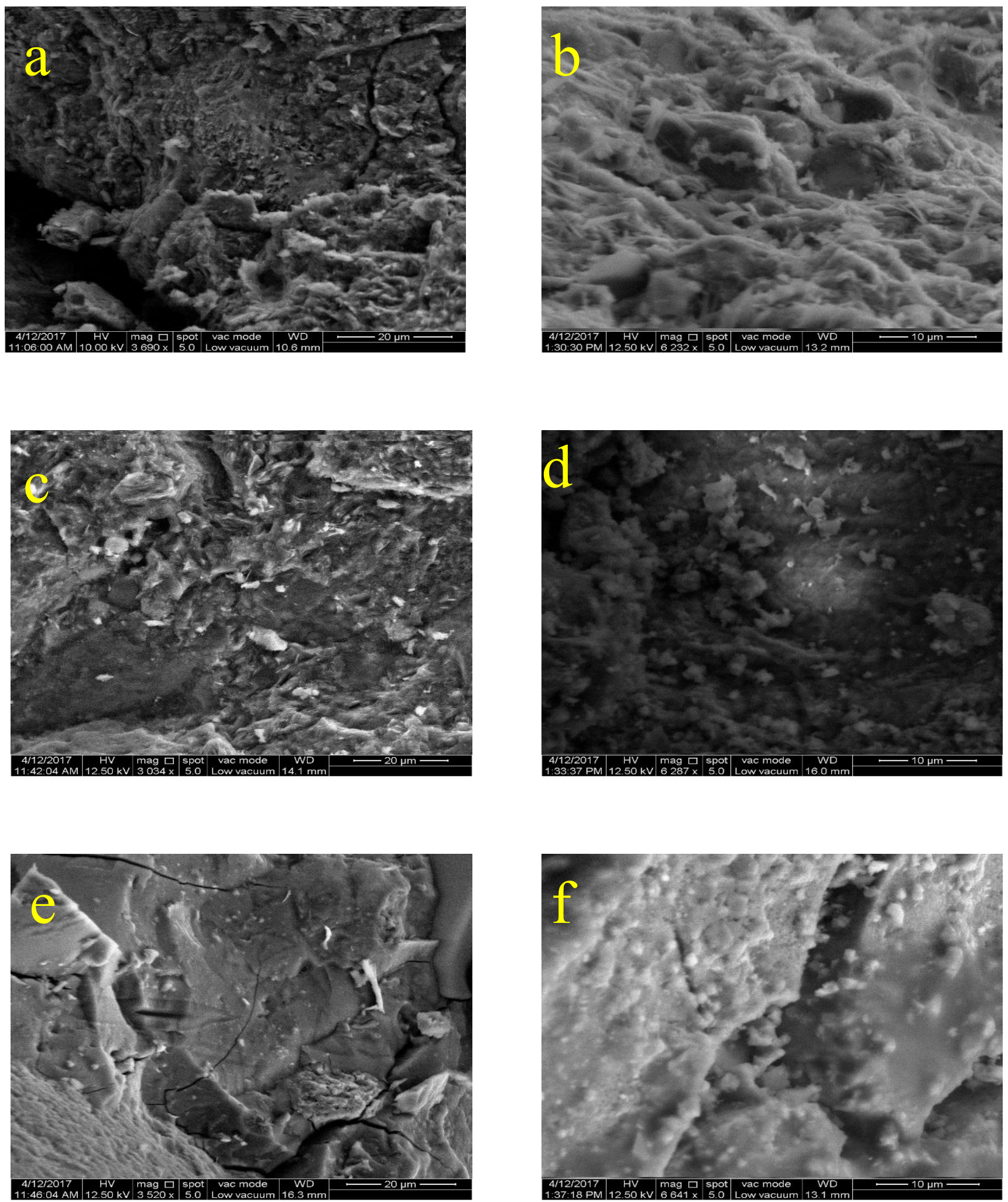

Fig.8. SEM pictures for metakaolin and GGS based Geopolymer concrete; (a) MK1* at 14 days, (b) MK1* at 60 days, (c) MK2* at 14 days, (d) MK2* at 60 days, (e) GGS* at 14 days, and (f) GGS* at 60 days. 

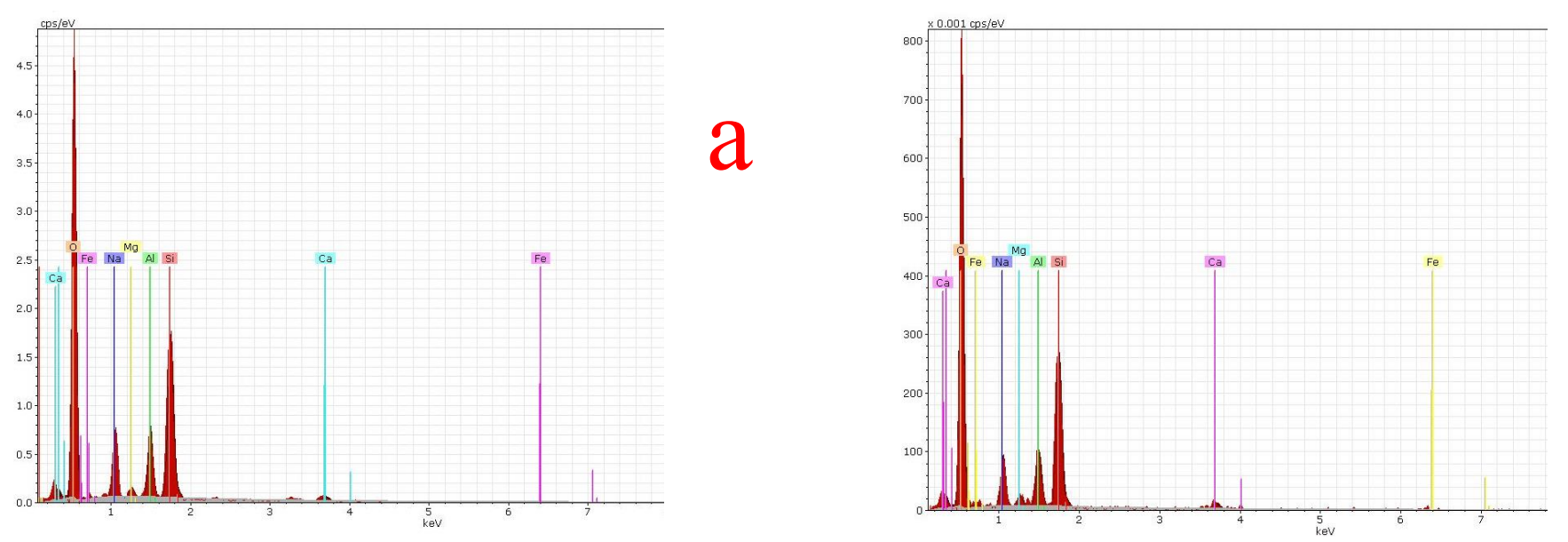

$\mathrm{b}$
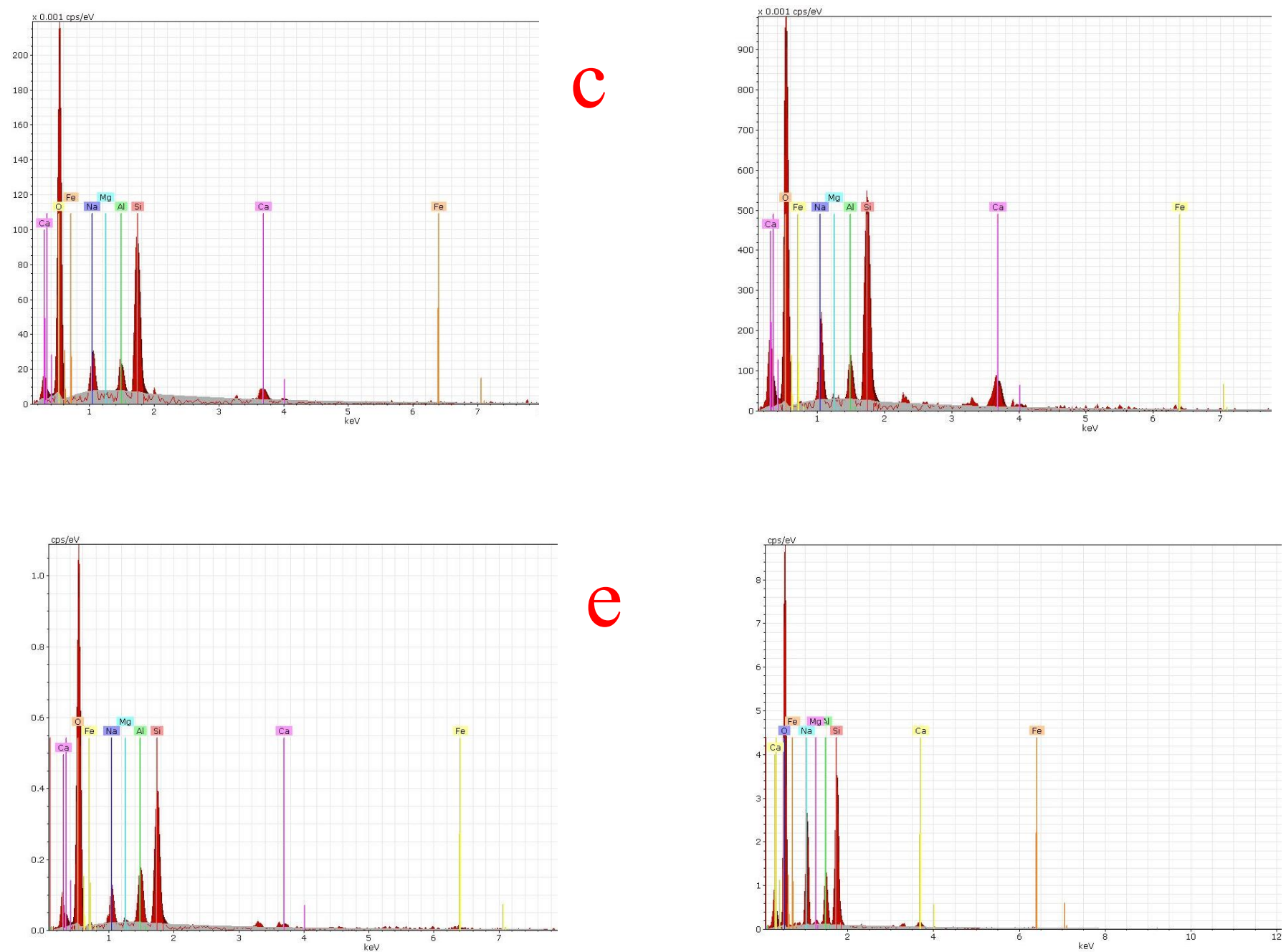

Fig. 9. EDX analysis for tly ash based Geopolymer concrete; (a) FA1* at 14 days, (b) FA1* at 60 days, (c) FA2* at 14 days, (d) FA2* at 60 days, (e) FA3* at 14 days, and (f) FA3* at 60 days. 


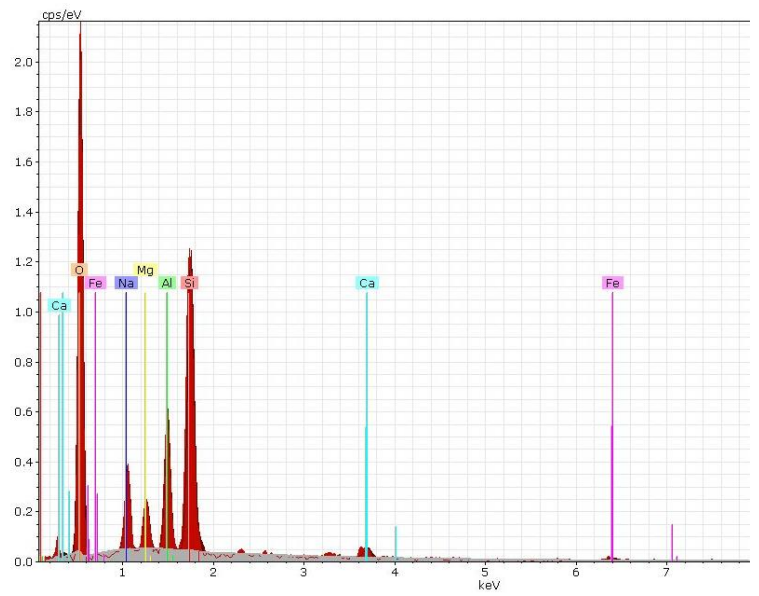

a
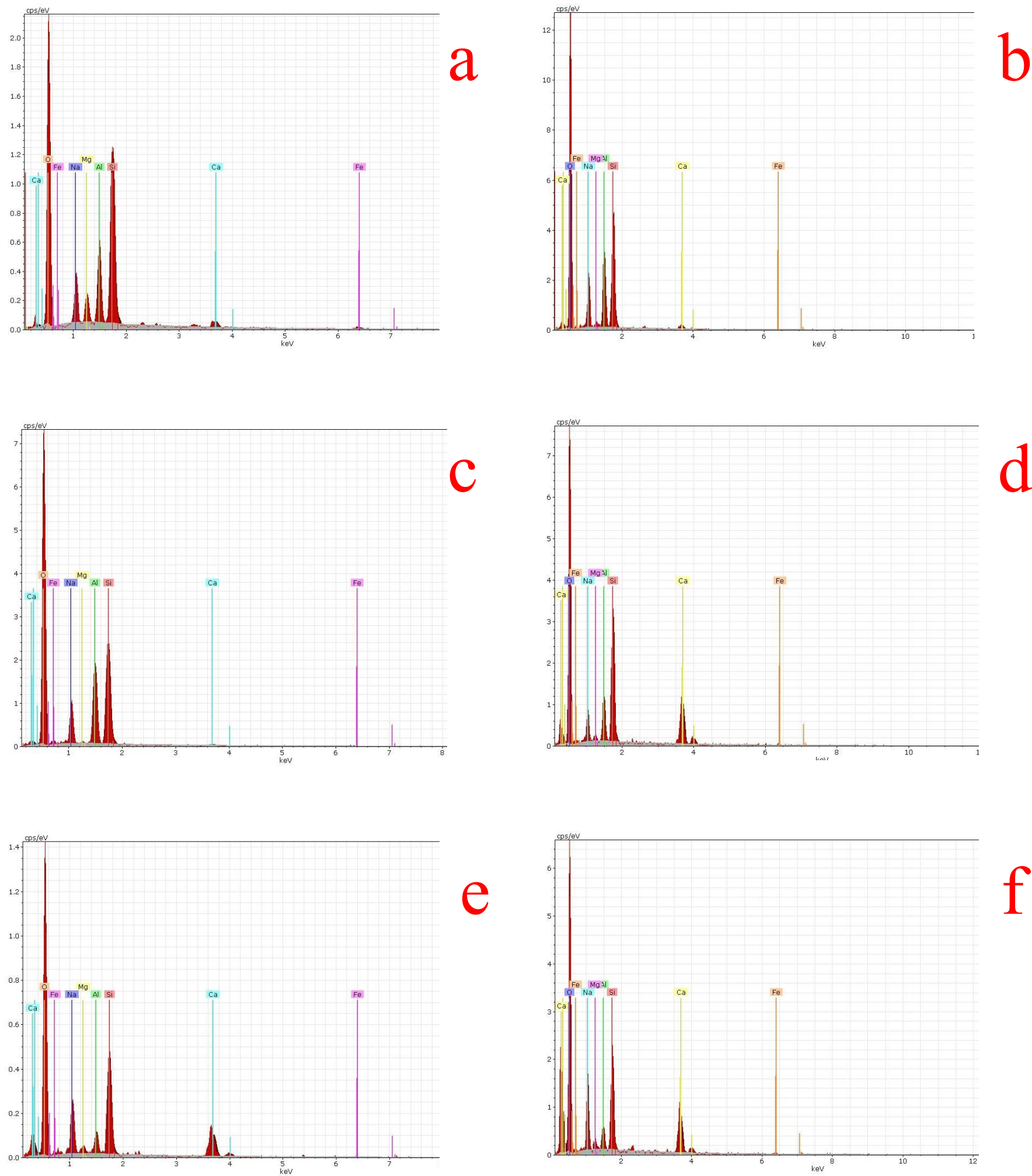

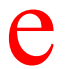

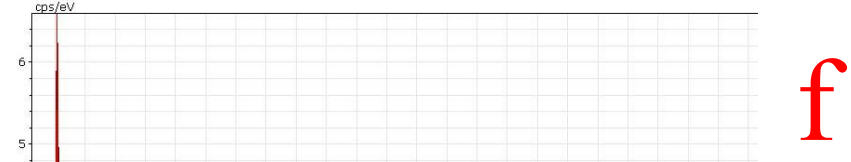

Fig. 10. EDX analysis for metakaolin and GGS based Geopolymer concrete; (a) MK1* at 14 days, (b) MK1* at 60 days, (c) MK2* at 14 days, (d) MK2* at 60 days, (e) GGS* at 14 days, and (f) GGS* at 60 days. 